\title{
Dynamic expression of Epac and Rap1 in mouse oocytes and preimplantation embryos
}

\author{
JUN-CHAO WANG, YING GENG, YING HAN, HAI-NING LUO and YUN-SHAN ZHANG \\ Center for Reproductive Medicine, Tianjin Central Hospital of Obstetrics and Gynaecology, \\ Tianjin 300100, P.R. China
}

Received September 15, 2017; Accepted February 8, 2018

DOI: $10.3892 /$ etm.2018.6253

\begin{abstract}
Cyclic adenosine monophosphate (cAMP) is an important secondary messenger that has long been recognized to control the initiation of meiosis through the activation of protein kinase A (PKA) in mammalian oocytes. However, PKA is not the only target for cAMP. Recent studies on cAMP-dependent and PKA-independent pathways suggest that Ras-related protein-1 (Rap1) is activated through its cAMP-responsive guanine exchange factors (cAMP-GEFs), which comprises the involvement of exchange proteins directly activated by cAMP (Epac) in various cellular processes. The aim of the present study was to investigate the possible implication of a cAMP/Epac/Rap1 pathway in mouse oocytes and embryos. Reverse transcription polymerase chain reaction and immunohistochemistry assays demonstrated the expression of Epac and Rap1 in oocytes and embryos at different stages. Immunofluorescene demonstrated that Epac and Rap1 had different dynamic subcellular localizations and expression patterns in oocytes and embryos at different stages. It was therefore indicated that Epac and Rap1 may have multiple and specific functions during oocyte maturation and embryonic development.
\end{abstract}

\section{Introduction}

Mammalian oocytes are physiologically arrested in the prophase of the first meiotic division. It is well established that meiosis is regulated by the levels of cyclic adenosine monophosphate (cAMP) within the oocyte $(1,2)$. The downstream pathway by which high cAMP levels prevent meiotic maturation has remained to be fully elucidated. Numerous studies on starfish, fish, amphibians and mammals support the hypothesis

Correspondence to: Professor Yun-Shan Zhang, Center for Reproductive Medicine, Tianjin Central Hospital of Obstetrics and Gynaecology, 156 Nankai Sanma Road, Tianjin 300100, P.R. China E-mail: successor317@aliyun.com

Key words: oocyte, embryo, cyclic adenosine monophosphate, exchange proteins directly activated by cAMP, Ras-related protein-1 that protein kinase $\mathrm{A}$ (PKA) has major roles in the maintenance of meiotic arrest (3-5).

Although increases in cAMP and activation of PKA are crucial for the induction and maintenance of meiotic arrest, the precise targets and downstream effectors of cAMP signaling have not been fully defined $(1,6)$. Initially, all effects of cAMP were attributed to the activation of PKA. The identification of a novel class of cAMP-binding proteins termed guanine nucleotide exchange factors (cAMP-GEFs) provided a means by which changes in cAMP yield actions that are independent of PKA $(7,8)$. Recently, the importance of PKA-independent signaling pathways in the regulation of oocyte maturation has been demonstrated $(9,10)$.

Exchange protein directly activated by cAMP (Epac) was discovered during a database search for proteins that may explain for the insensitivity to cAMP-induced activation of the small GTPase Ras-related protein-1 (Rap1) (7,8). To date, two isoforms of Epac (Epac1 and Epac2) have been identified. Epac1 and Epac2 exhibit distinct expression patterns in mature and developing tissues. In particular, Epac1 mRNA is expressed ubiquitously, whereas Epac2 mRNA is predominantly expressed in the brain (8). Accordingly, the present study focused on the expression pattern of Epac1. Epac is a Rap1-specific cAMP-GEF and activates Rap1 directly as an effector molecule of cAMP, with no involvement of PKA. The cAMP/Epac/Rapl pathway has been demonstrated and implicated in numerous cell systems (11-13). It is involved in a variety of cellular processes, including secretion (14), cell adhesion (15), intercellular junction formation (16), apoptosis (17), cell proliferation (18) and cell differentiation (19). The objectives of the present study were to investigate whether a cAMP/Epac/Rap1 pathway exists in oocyte maturation as a cAMP-dependent but PKA-independent factor.

\section{Materials and methods}

Animals. Animal care and handling was performed in accordance with the Animal Research Committee guidelines of the Institute of Zoology, Chinese Academy of Sciences. Unless otherwise stated, ovaries and ooctyes were obtained from a total of 20, 5-week-old B6D2F1 strain mice (C57BL/6 x DBA/2J) weighing $18-20$ g. C57BL/6 female mice $(n=10)$ and DAB/2 male $(n=5)$ mice were purchased from Shanghai SLAC Laboratory Animal Co., Ltd. (Shanghai, China). Animals were housed at 
a controlled temperature $\left(22-24^{\circ} \mathrm{C}\right)$ and were subjected to a 12-h light/dark cycle (lights on from 6:00 until-18:00). Animals received ad libitum access to food and tap water.

Immunohistochemistry. Ovaries from 5-week-old B6D2F1 strain mice (C57BL/6 x DBA/2J) were fixed overnight in Bouin's solution and then processed into paraffin wax blocks. Sections were cut at a thickness of $5 \mu \mathrm{m}$ and mounted on poly-l-lysine-coated glass slides. Sections were de-paraffinized in xylene, rehydrated in a graded ethanol series and washed in deionized water for $5 \mathrm{~min}$. The sections were next heated in citrate buffer $\left(\mathrm{pH} \mathrm{9.0)} \mathrm{for} 30 \mathrm{~min}\right.$ in a water bath at $96^{\circ} \mathrm{C}$. The samples were treated with $0.3 \%$ hydrogen peroxide in absolute methanol for $10 \mathrm{~min}$ at room temperature (RT) to inhibit endogenous peroxidase activity. Non-specific protein binding was blocked by incubation with $3 \%$ normal donkey and goat serum for Epac and Rap1, respectively, in PBS for $10 \mathrm{~min}$ at RT. Working solutions of primary antibodies 91:100 dilution) for anti-Epac1 (cat. no. sc-8879) and anti-Rap1 (cat. no. sc-65; both from Santa Cruz Biotechnology, Inc., Dallas, TX, USA) were applied to the sections overnight at $4^{\circ} \mathrm{C}$. Subsequently, two peroxidase-conjugated donkey anti-goat (cat. no. sc-2059) and goat anti-rabbit immunoglobulin $\mathrm{G}$ ( $\mathrm{IgG}$ ) secondary antibodies (cat. no. sc-2054; both Santa Cruz Biotechnology, Inc.), diluted 1:2,000 in PBS containing $1.5 \%$ bovine serum albumin (BSA), were applied for $1 \mathrm{~h}$ at $37^{\circ} \mathrm{C}$. Labeling was visualized using 3,3'-diaminobenzidine and counterstained with hematoxylin at RT for $5 \mathrm{~min}$. After each step, the sections were rinsed with PBS. The control sections were incubated with PBS only, without the primary antibody. The experiments were performed at least three times for each antibody staining.

Oocyte and embryo retrieval. All oocytes and zygotes were obtained from the 5-week-old B6D2F1 female mice (C57BL/6 females x DBA/2J males).

The culture medium was G1 medium (Vitrolife, Göteborg, Sweden) containing $4 \mathrm{mg} / \mathrm{ml}$ BSA (Sigma-Aldrich; Merck $\mathrm{KGaA}$, Darmstadt, Germany). Oocytes were cultured in an incubator at $37^{\circ} \mathrm{C}$ with $6 \% \mathrm{CO}_{2}$. Germinal vesicle $(\mathrm{GV})$ oocytes were isolated from ovaries into G1 medium containing dibutyryl cAMP (100 $\mu \mathrm{g} / \mathrm{ml}$; Sigma-Aldrich; Merck KGaA) to prevent resumption of meiosis. Metaphase II (MII) stage oocytes were recovered from ampullae from mice superovulated by intraperitoneal injection of $7.5 \mathrm{IU}$ of pregnant mare serum gonadotropin followed by $7.5 \mathrm{IU}$ of human chorionic gonatropin (hCG) $48 \mathrm{~h}$ later. Cumulus cells were removed with $0.1 \mathrm{mg} / \mathrm{ml}$ hyaluronidase (Sigma-Aldrich; Merck KGaA) by pipetting. To collect synchronized embryos, superovulated females were caged $13 \mathrm{~h}$ after hCG injection with male mice for $1.5 \mathrm{~h}$ and vaginal plugs were checked the next morning. Zygotes (1-cell embryos) were collected from the oviducts $18-20 \mathrm{~h}$ after mating. Early 2 -cell, 4-cell and 8-cell embryos were collected at 44, 54 and $68 \mathrm{~h}$ after mating, respectively.

Immunofluorescene. Mouse oocytes were fixed with $2 \%$ formaldehyde for $15 \mathrm{~min}$ at $37^{\circ} \mathrm{C}$ and permeabilized with $0.02 \%$ Triton $\mathrm{X}-100$ for $1 \mathrm{~h}$ at $37^{\circ} \mathrm{C}$. To determine the expression of Epac and Rap1, the fixed oocytes were incubated with goat anti-Epac1 (sc-8879; Santa Cruz Biotechnology, Inc.) polyclonal antibodies and rabbit anti-Rap1 (sc-65; Santa Cruz Biotechnology,
Inc.) polyclonal antibodies for $1 \mathrm{~h}$ at $37^{\circ} \mathrm{C}$. After being washed with PBS, oocytes were transferred to a solution with secondary antibodies: Cy3-conjugated anti-goat IgG (1:500; cat. no. 705-165-003; Jackson ImmunoResearch Laboratoris, Inc., West Grove, PA, USA) and Cy3-conjugated anti-rabbit IgG (1:500; cat. no. 111-165-003; Jackson ImmunoResearch Laboratoris, Inc.) for $1 \mathrm{~h}$ at $37^{\circ} \mathrm{C}$. All of the secondary antibodies were purchased from Jackson Laboratories (Bar Harbor, ME, USA). DAPI (0.2 $\mu \mathrm{g} / \mathrm{ml}$, DA0001, Sigma-Aldrich) was used to stain the nuclei for $5 \mathrm{~min}$ at RT. Slides were examined using a laser-scanning confocal microscope with a $63 \mathrm{x}$ oil immersion objective lens and a Leica SP2 krypton-argon ion laser (Leica Microsystems, Wetzlar, Germany) for the simultaneous excitation of fluorescence for proteins and DAPI for DNA.

Reverse transcription polymerase chain reaction (RT-PCR) analysis. mRNA was prepared from 100 MII-stage oocytes using TRIzol reagent (Invitrogen; Thermo Fisher Scientific, Inc., Waltham, MA, USA) according to the manufacturer's instructions. Standard complentary DNA synthesis by reverse transcription of the RNA was then performed using random primers and SuperScript ${ }^{\mathrm{TM}}$ III RNase H-Reverse Transcriptase (Invitrogen; Thermo Fisher Scientific, Inc.). Epac1 and Rapla mRNA were detected by RT-PCR with mRNA primer pairs using hot start Taq DNA polymerase (Takara Bio Inc., Shiga, Japan). PCR was performed in 96-well plates with $2110 \mathrm{x}$ Taq Buffer, $10 \mathrm{mM}$ deoxy-ribonucleoside triphosphate, $25 \mathrm{mM}$ $\mathrm{MgCL}_{2}$, primers at a final concentration of $0.2 \mu \mathrm{m}$ and a cDNA sample derived from $5 \mathrm{ng}$ total RNA in a total volume of $20 \mu \mathrm{l}$. Following $2 \mathrm{~min}$ incubation at $50^{\circ} \mathrm{C}$ followed by $10 \mathrm{~min}$ incubation at $95^{\circ} \mathrm{C}$, the samples were subjected to 40 cycles of amplification $\left(95^{\circ} \mathrm{C}\right.$ for $15 \mathrm{sec}, 60^{\circ} \mathrm{C}$ for $\left.1 \mathrm{~min}\right)$ and dissociation $\left(95^{\circ} \mathrm{C}\right.$ for $15 \mathrm{sec}, 60^{\circ} \mathrm{C}$ for $1 \mathrm{~min}$ and $95^{\circ} \mathrm{C}$ for $\left.15 \mathrm{sec}\right)$. All the test reactions were accompanied by negative controls and were performed with at least two independent preparations. The PCR primers were non-dimerizing under the conditions employed and were typically intron-flanking. They were designed according to the mouse Epac1 mRNA sequence with the GenBank accession no. NM_144850.1: Sense, 5'-TCCCCT CCTGTCATCCCC-3' and antisense, 5'-GCCATCATCCGC ATCTTCTC-3' [product length, 116 base pairs (bp)] and Rapla mRNA sequence with the accession no. NM_145541.4: Sense, 5'-TTCTGCAAAGTCAAAGATCAACG-3' and antisense, 5'-TTTTAGGCTTCTTCTTTTCCACTG-3' (product length, $95 \mathrm{bp}$ ). As a positive control, the mRNA for GAPDH was amplified using the following primers (based on accession no. NM_001001303): Sense, 5'-TGACGTGCCGCCTGGAGA AA-3' and antisense, 5'-AGTGTAGCCCAAGATGC-CCT TCAG-3' (product length, 98 bp). The PCR products were separated using $1.0 \%$ agarose gel electrophoresis, ethidium bromide staining and UV transillumination followed by capture with a charge-coupled device camera. Fragment sizes were estimated using a 100 bp DNA ladder (M106R; Genscript Biotech Corporation, Nanjing, China).

\section{Results}

Expression of Epacl and Rapla mRNA in MII-stage oocytes. The expression of Epac1 and Rapla mRNAs was detected in the MII-stage oocytes using RT-PCR analysis. This result 


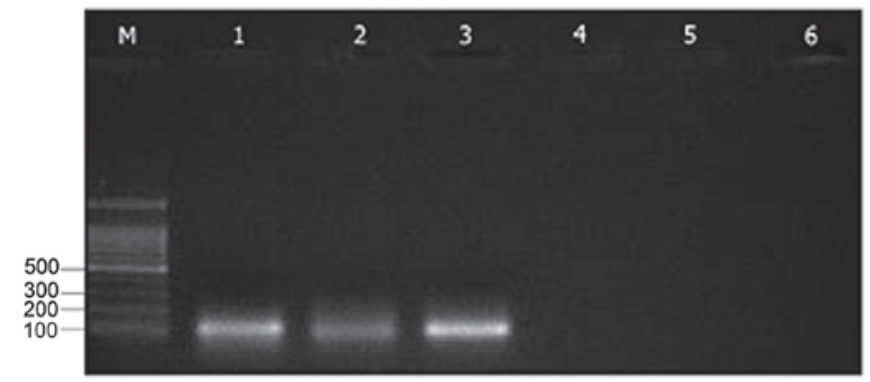

Figure 1. Reverse transcription polymerase chain reaction performed on 100 MII-stage mouse oocytes with primers specific for Epac1 (product length, $116 \mathrm{bp}$ ), Rap1 (product length, $95 \mathrm{bp}$ ) and GAPDH (product length, 98 bp). Lanes: M, 100-bp DNA ladder; 1-3, amplification products for Epac1, Rap1 and GAPDH, respectively; 4-6, negative controls without reverse transcriptase, RNA and complementary DNA in the reaction tube, respectively. Rap1, Ras-related protein-1; Epac, exchange proteins directly activated by cyclic adenosine monophosphate.

demonstrated Epac1 and Rapla mRNA is expressed in MII-stage mouse oocytes (Fig. 1).

Localization of Epacl and Rapla in the adult mouse ovary. The existence of Epac1 in the human ovary has been demonstrated by northern blotting (8). In addition, the cAMP/Epac1/Rapla pathway has been indicated to participate in the proliferation of immature rat granulosa cells and the regulation of progesterone secretion by luteinizing human granulose cells $(20,21)$. However, data regarding the specific expression patterns of these two genes in the female germline are limited. To address this, the sections of mouse ovaries were stained to analyze the distribution of Epac1 and Rapla proteins throughout oogenesis. Immunostaining indicated that the two proteins were expressed throughout the entire ovary (Fig. 2B-E). The two proteins were detected in either germ or follicle cell tissues throughout the different stages of oocyte development, from primordial follicles to Graafian follicles and were distributed throughout the cytoplasm. Epac1 immunostaining in oocyte and granulosa cells appeared uniform (Fig. 2B and C). By contrast, the immunostaining for Rapla in oocytes appeared stronger than that in granulosa cells (Fig. 2D and E).

Localization of Epac during meiotic maturation of mouse oocytes. The present study examined the dynamic localization of Epac1 in mouse oocytes using immunocytochemistry and confocal microscopy. At the GV stage, Epac was first seen as small accumulations scattered in the cytoplasm (Fig. 3A). After GV breakdown (GVBD), the chromatin condensed towards the center of the oocyte. A network of small clusters, distributed uniformly throughout the cytoplasm, then became evident (Fig. 3B). Following the migration of the condensed meiotic chromosomes to the cortex of the oocyte, small clusters became polarized and concentrated at opposite ends (Fig. 3C). However, at the MII stage, when the first polar body is extruded and the MII spindle is already established, the accumulations appeared to become reduced and spread out in the ooplasm (Fig. 3D). When the MII oocyte had been fertilized and developed into a one-cell stage zygote, the network of clusters almost disappeared and Epac became uniformly distributed throughout the embryo (Fig. 3E).

Differential expression of Rapla protein in oocytes and embryos. As a member of the Ras-like small GTPase superfamily, Rap1 has been implicated in the regulation of a variety of cellular processes. However, its role in oocyte maturation and early embryonic development has remained to be elucidated. Using immunocytochemistry, it was evidenced that Rapla expression patterns differed between mouse oocytes and early preimplantation embryos. During different stages of oocyte maturation, Rapla was dispersed uniformly as small punctuations throughout the cytoplasm (Fig. 4A). When oocytes were fertilized and allowed to develop into 1-cell zygotes, the small punctuations aggregated into visible clusters of particles that mainly occupied the cortical region of blastomeres (Fig. 4B). This phenomenon was evident even in 2-cell and 4-cell stage embryos (Fig. 4C and D) and persisted in subsequent early preimplantation embryos (Fig. 4E). In general, the localization of Rapla is variable and depends on the cell type $(22,23)$. The activation of Rapla and the subsequent response are determined by the local environment. In addition, the spatial and temporal localization of Rap1 is associated with different cellular functions (24). Therefore, it is speculated that Rapla may have a different function in oocyte maturation from that in early embryonic development.

\section{Discussion}

The present study indicated a mutually exclusive dynamic expression of Epac1 and Rapla in oocytes and embryos. Epac1 has a unique distribution during oocyte maturation, which disappeared upon entering the MII stages. Rapla exhibited its typical expression only beginning from pronuclear-stage embryos and persisting in subsequent early preimplantation embryos (Fig. 4A-E). As the limitation of our experimental research method, the 8-cell stage embryo showed in Fig. 4E may appear the cell $<8$ for the embryo was squeezed on a glass slide. The different and dynamic localizations of Epac1 and Rapla are likely to be crucial determinants of the functions of these proteins. It is anticipated that, as with PKA, the multiple functions of this pathway may depend on the localization of these two proteins (25).

It is thought that a high level of cAMP in the oocyte maintains putative initiator proteins in a phosphorylated (inactive) state, inhibiting oocyte maturation and that the activation of initiator proteins by dephosphorylation via mechanisms that remain elusive induces maturation-promoting factor (MPF) activity $(26,27)$. MPF is activated upon GVBD and increases until it reaches a plateau at the end of the first meiotic M-phase $(28,29)$. MPF is rapidly reactivated to enter meiosis II and is maintained at a high level during the MII phase arrest. The discrete sets of steps through which cAMP activates or inactivates MPF are still under investigation. There is a consensus that PKA has major roles in this process. Thus, the change of cAMP levels within the oocyte leads to the activation of MPF in a PKA-dependent manner. However, the inhibitory role of cAMP on meiosis contradicts the fact that maturation is stimulated by a surge of the gonadotrophins, luteinizing hormone and follicle stimulating hormone (30), both of which stimulate cAMP production in the somatic cells of follicles and increase the level of cAMP in 


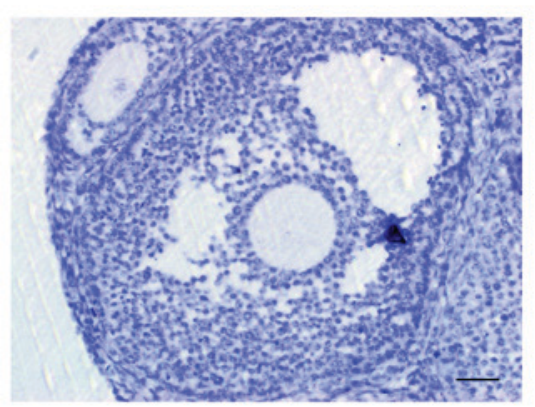

C

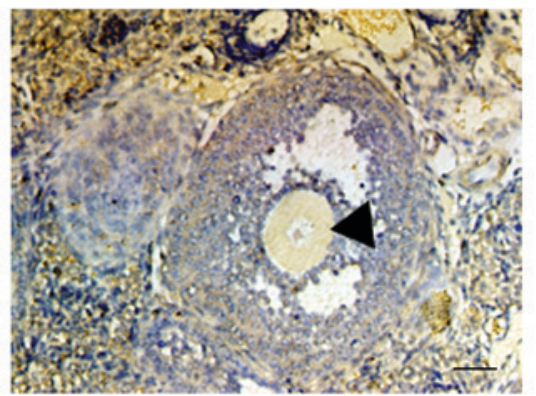

$\mathrm{E}$

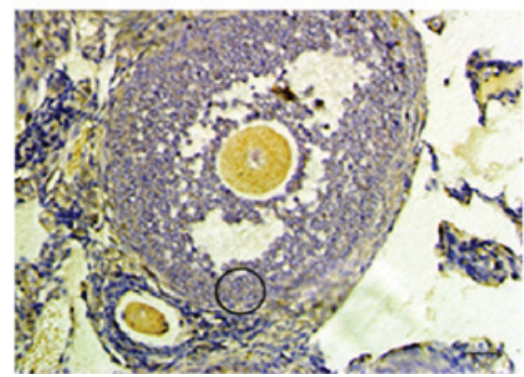

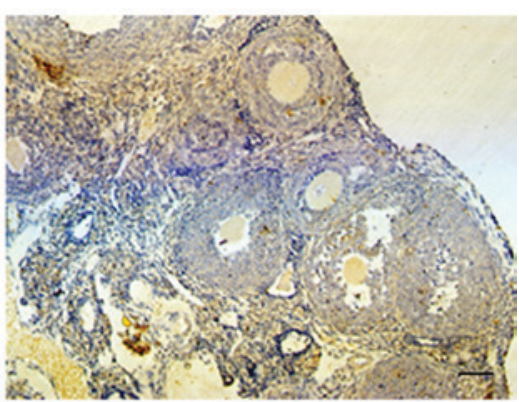

D

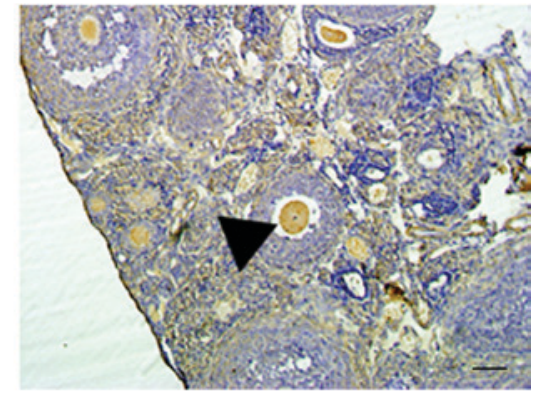

Figure 2. Ovarian localization of Epac and Rap1 proteins determined by immunohistochemistry. (A) Negative control. The control sections were incubated with PBS only, without the primary antibody and the blue appearance is the result of hematoxylin staining. (B-E) Ovarian sections at various stages of oogenesis with immunostaining for (B and C) Epac and (D and E) Rap1. Different stages of follicles were showed in (B and D) primary follicles, secondary follicles and antral follicles. Arrowheads indicate antral stage follicles in (C and D) and the circle indicates cumulus and granulosa cells in E (scale bar, $20 \mu \mathrm{m}) . \mathrm{Rap} 1$, Ras-related protein-1; Epac, exchange proteins directly activated by cyclic adenosine monophosphate.

oocytes via gap junctions (31). Studies have attempted to explain this apparent paradoxical action of cAMP concerning the spatial localization of the downstream signaling proteins involving the cAMP-PKA pathway (32). However, it is also possible that PKA-independent pathways (e.g., the cAMP/Epac/Rap1 pathway) are involved.

Epac has emerged as an important target of cAMP in a variety of processes. The isomers contain a cAMP-binding domain with significant sequence homology to the R subunits of PKA and a GEF domain that functions to exchange GTP for $\operatorname{GDP}(7,8)$. Epac was first demonstrated to be an exchange factor for the small GTPase Rap1. GTP-bound Rap1 causes the activation and initiation of a cascade of protein kinases of the mitogen-activated protein kinase (MAPK) signal transduction pathway $(21,33,34)$. Numerous protein kinases and phosphatases have been suggested to participate in the process of meiotic arrest and progression in mice. The MAPK extracellular signal-regulated kinase $1 / 2$ is one of the protein kinases that may participate directly and indirectly in the regulation of meiotic resumption of oocytes $(35,36)$.
The MAPK pathway has a crucial role in the reactivation of MPF after meiosis I and thereafter in the maintenance of MII arrest (37). It may be speculated that the cAMP/Epac/Rap1 pathway regulates the inhibition and progression of mouse oocyte maturation through activating the MAPK pathway. Of course, further experiments should be performed to test this hypothesis.

In most cases, the involvement of Epac compensates for the role of PKA and it is frequently intrinsically linked to the cAMP/PKA pathway (15). Dual control involving PKA and Epac may enhance the dynamic range of cAMP signaling (22). PKA activity per se is not sufficient, and it is rather the complex cAMP signaling pathways that regulate meiotic arrest and progression.

In conclusion, the present study was the first, to the best of our knowledge, to demonstrate that Epac and Rap1 display dynamic and characteristic expression patterns in mouse oocytes and embryos. These results offer a basis for further research to elucidate the function of the cAMP/Epac/Rap1 pathway in oocytes and embryos. 
A

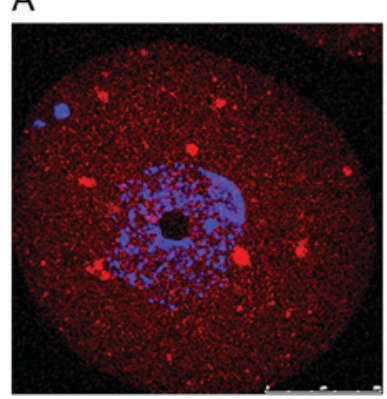

B

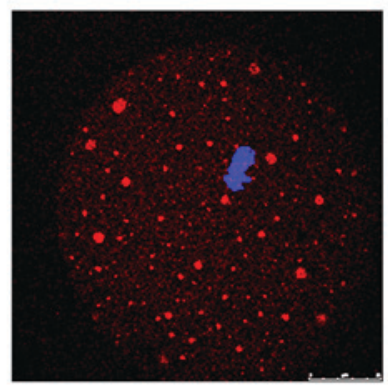

C

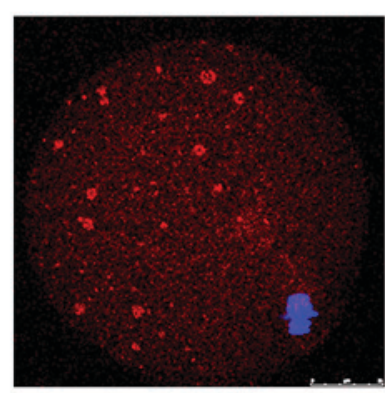

$\mathrm{D}$

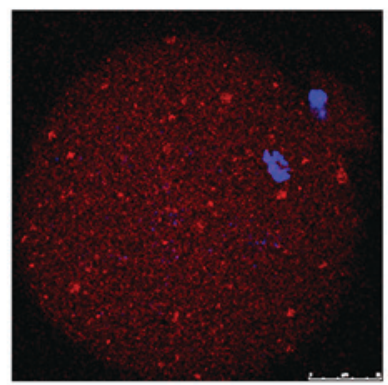

E

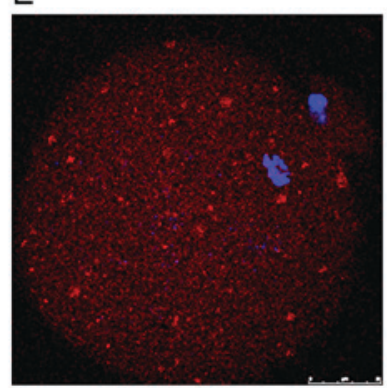

Figure 3. Localization pattern of Epac during oocyte maturation in vivo and one-cell embryos. (A-E) Different stages of oocytes and embryos were examined for Epac expression (red) using immunostaining. Chromatin was stained with DAPI (blue). (A) Germinal vesicle oocyte. (B) MI oocyte with chromosomes located towards the center of the oocyte. (C) Late MI oocyte. (D) MII oocyte. (E) 1-cell embryos (scale bar, $25 \mu \mathrm{m}$ ). Epac, exchange proteins directly activated by cyclic adenosine monophosphate. M, metaphase.

\section{Acknowledgements}

Not applicable.

\section{Funding}

This research was funded by the Key Project of the Health Industry in Tianjin ('Functional Research of Cryopreserved Human Ovary Tissue', 2012-2015; grant no. 12ZK101). It was also supported by a grant from the Tianjin Health and Family Planning Commission ('Research on miRNA/SIRT1 regulating oocyte apoptosis in premature ovary failure', 2015-2018; grant no. $15 \mathrm{KG} 141)$.

\section{Availability of data and materials}

The analysed data sets generated during the study are available from the corresponding author on reasonable request.
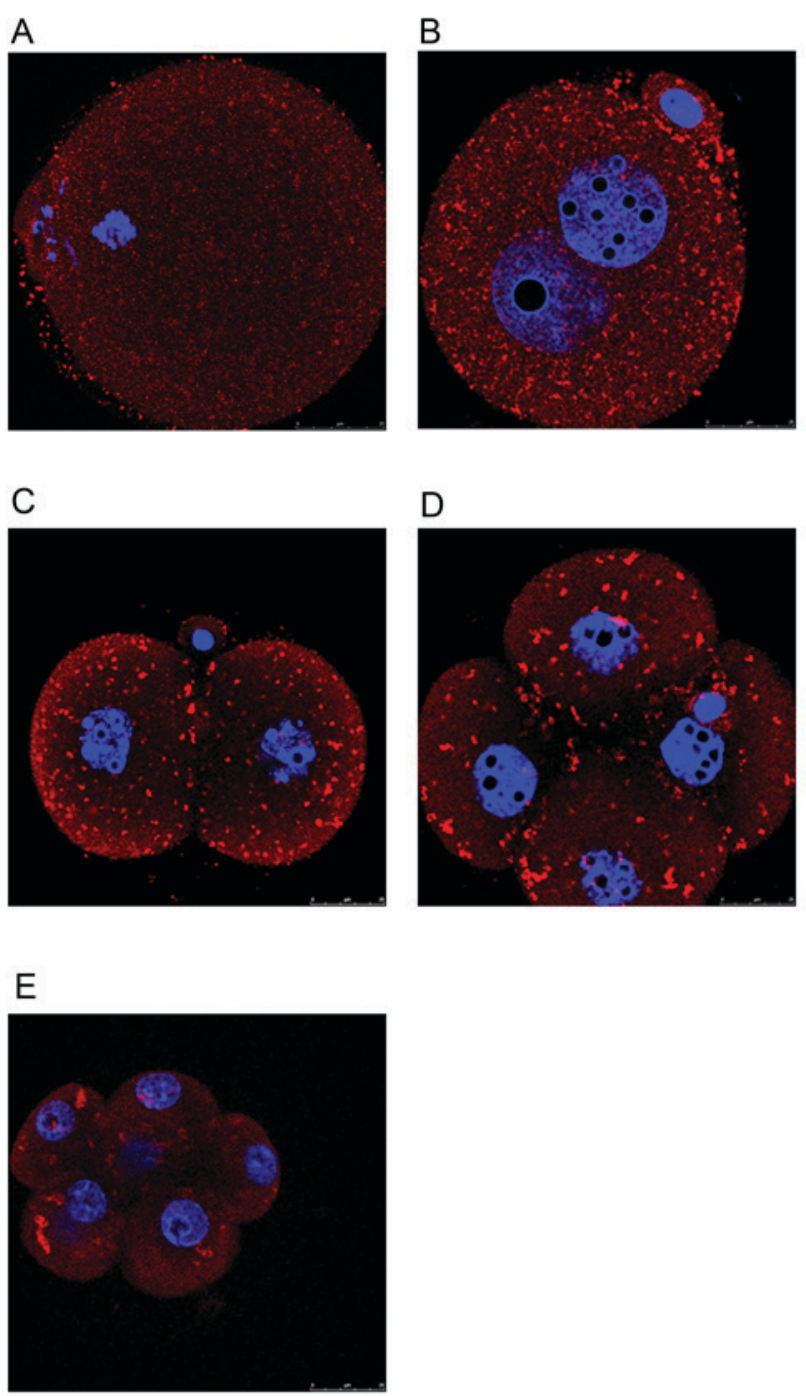

Figure 4. Expression pattern of Rap1 on oocytes, as well as early preimplantation embryos at different stages. Embryos at different stages were examined for Rap1 expression (red) using immunostaining. Chromatin was stained with DAPI (blue). (A) Metaphase II oocytes. (B) 1-cell stage embryo. (C) 2-cell stage embryo. (D) 4-cell stage embryo. (E) 8-cell stage embryo (scale bar, $25 \mu \mathrm{m}$ ).

\section{Authors' contributions}

JW was involved in project development and wrote the manuscript. YG made substantial contributions to the acquisition, analysis and interpretation of data. YH was involved in data collection and analysis. HL was involved in designing the experiment and revising the manuscript, and agreed to be accountable for all aspects of the work in ensuring that questions related to the accuracy or integrity of any part of the work are appropriately investigated and resolved. YZ was involved in the design and execution of the study, as well as data analysis.

\section{Ethical approval and consent to participate}

The study protocol was approved by the ethics committee of the Center for Reproductive Medicine, Tianjin Central Hospital of Obstetrics and Gynaecology (Tianjin, China). 


\section{Consent for publication}

Not applicable.

\section{Competing interests}

The authors declare that they have no competing interests.

\section{References}

1. Conti M, Andersen CB, Richard F, Mehats C, Chun SY, Homer K, Jin C and Tsafriri A: Role of cyclic nucleotide signaling in oocyte maturation. Mol Cell Endocrinol 187: $153-159,2002$.

2. Eppig JJ, Vivieros MM, Marin-Bivens $C$ and De La Fuente R: (2004) in: The Ovary, (Leung PCK \& Adashi EY, eds), Elsevier, Academic Press pp113-129, 2004.

3. Meijer L, Dostmann W, Genieser HG, Butt E and Jastorff B: Starfish oocyte maturation: Evidence for a cyclic AMP-dependent inhibitory pathway. Dev Biol 133: 58-66, 1989.

4. Jalabert G, Fostier A, Breton B and Weil C in: Vertebrate Endocrinology: Fundamentals and Biomedical Implications (Pang PKT \& Schreibman MP, eds), Vol 4A, New York Academic Press pp113-129, 1991.

5. Chaube SK and Haider S: J Exp Zool 277: 166-170, 1997.

6. Josefberg LB and Dekel N: Translational and post-translational modifications in meiosis of the mammalian oocyte. Mol Cell Endocrinol 187: 161-171, 2002.

7. de Rooij J, Zwartkruis FJ, Verheijen MH, Cool RH, Nijman SM, Wittinghofer A and Bos JL: Epac is a Rap1 guanine-nucleotide-exchange factor directly activated by cyclic AMP Nature 396: 474-477, 1998.

8. Kawasaki H, Springett GM, Mochizuki N, Toki S, Nakay M, Matsuda M, Houseman DE and Graybiel AM: A family of cAMP-binding proteins that directly activate Rap1. Science 282 2275-2279, 1998.

9. Schmitt A and Nebreda AR: Inhibition of xenopus oocyte meiotic maturation by catalytically inactive protein kinase a. Proc Natl Acad Sci USA 99: 4361-4366, 2002.

10. Pace MC and Thomas P: Steroid-induced oocyte maturation in Atlantic croaker (Micropogonias undulatus) is dependent on activation of the phosphatidylinositol 3-kinase/Akt signal transduction pathway. Biol Reprod 73: 988-996, 2005.

11. Brennesvik EO, Ktori C, Ruzzin J, Jebens E, Shepherd PR and Jensen J: Adrenaline potentiates insulin-stimulated PKB activation via cAMP and Epac: Implications for cross talk between insulin and adrenaline. Cell Signal 17: 1551-1559, 2005.

12. Hucho TB, Dina OA and Levine JD: Epac mediates a cAMP-to-PKC signaling in inflammatory pain: An isolectin B4(+) neuron-specific mechanism. J Neurosci 25: 6119-6126, 2005

13. Branham MT, Mayorga LS and Tomes CN: Calcium-induced acrosomal exocytosis requires cAMP acting through a protein kinase A-independent, Epac-mediated pathway. J Biol Chem 281: 8656-8666, 2006.

14. Robert S: Regulation of the amyloid precursor protein ectodomain shedding by the 5-HT4 receptor and Epac. FEBS Lett 579: 1136-1142, 2005.

15. Rangarajan S, Enserink JM, Kuiperij HB, de Rooij J, Price LS, Schwede F and Bos JL: Cyclic AMP induces integrin-mediated cell adhesion through Epac and Rap1 upon stimulation of the beta 2-adrenergic receptor. J Cell Biol 160: 487-493, 2003.

16. Fukuhara S, Sakurai A, Sano H, Yamagishi A, Somekawa S, Takakura N, Saito Y, Kangawa K and Mochizuki N: Cyclic AMP potentiates vascular endothelial cadherin-mediated cell-cell contact to enhance endothelial barrier function through an Epac-Rap1 signaling pathway. Mol Cell Biol 25: 136-146, 2005.

17. Kwon G, Pappan KL, Marshall CA, Schaffer JE and McDaniel ML: cAMP Dose-dependently prevents palmitate-induced apoptosis by both protein kinase A- and cAMP-guanine nucleotide exchange factor-dependent pathways in beta-cells. J Biol Chem 279: 8938-8945, 2004.
18. Misra UK and Pizzo SV: Coordinate regulation of forskolin-induced cellular proliferation in macrophages by protein kinase A/cAMP-response element-binding protein (CREB) and Epac1-Rapl signaling: Effects of silencing CREB gene expression on Akt activation. J Biol Chem 280: 38276-38289, 2005.

19. Bryn T, Mahic M, Enserink JM, Schwede F, Aandahl EM and Tasken K: The cyclic AMP-Epac1-Rap1 pathway is dissociated from regulation of effector functions in monocytes but acquires immunoregulatory function in mature macrophages. J Immunol 176: 7361-7370, 2006.

20. Gonzalez-Robayna IJ, Falender AE, Ochsner S, Firestone GL and Richards JS: Follicle-Stimulating hormone (FSH) stimulates phosphorylation and activation of protein kinase B (PKB/Akt) and serum and glucocorticoid-lnduced kinase (Sgk): Evidence for A kinase-independent signaling by FSH in granulosa cells. Mol Endocrinol 14: 1283-1300, 2000.

21. Chin EC and Abayasekara DR: Progesterone secretion by luteinizing human granulosa cells: A possible cAMP-dependent but PKA-independent mechanism involved in its regulation. J Endocrinol 183: 51-60, 2004.

22. Beranger F, Goud B, Tavitian A and de Gunzburg J: Association of the Ras-antagonistic Rap1/Krev-1 proteins with the Golgi complex. Proc Natl Acad Sci 88: 1606-1610, 1991.

23. Maridonneau-Parini I and de Gunzburg J: Association of rap1 and rap2 proteins with the specific granules of human neutrophils Translocation to the plasma membrane during cell activation. J Biol Chem 267: 6396-6402, 1992.

24. Zwartkruis FJ and Bos JL: Ras and Rapl: Two highly related small GTPases with distinct function. Exp Cell Res 253: 157-165, 1999.

25. Dodge-Kafka KL, Soughayer J, Pare GC, Carlisle Michel JJ, Langeberg LK, Kapiloff MS and Scott JD: The protein kinase A anchoring protein mAKAP coordinates two integrated cAMP effector pathways. Nature 437: 574-578, 2005.

26. Dekel N: Protein phosphorylation/dephosphorylation in the meiotic cell cycle of mammalian oocytes. Rev Reprod 1: 82-88, 1996.

27. Duckworth BC, Weaver JS and Ruderman JV: G2 arrest in Xenopus oocytes depends on phosphorylation of $\operatorname{cdc} 25$ by protein kinase A. Proc Natl Acad Sci USA 99: 16794-16799, 2002.

28. Choi T, Aoki F, Mori M, Yamashita M, Nagahama Y and Kohomoto K: Activation of $\mathrm{p} 34 \mathrm{cdc} 2$ protein kinase activity in meiotic and mitotic cell cycles in mouse oocytes and embryos. Development 113: 789-795, 1991.

29. Verlhac MH, Kubiak JZ, Clarke HJ and Maro B: Microtubule and chromatin behavior follow MAP kinase activity but not MPF activity during meiosis in mouse oocytes. Development 120: 1017-1025, 1994.

30. Pincus G and Enzmann EV: The comparative behavior of mammalian eggs in vivo and in vitro: I. the activation of ovarian eggs. J Exp Med 62: 655-675, 1935.

31. Webb RJ, Marshall F, Swann K and Carroll J: Follicle-stimulating hormone induces a gap junction-dependent dynamic change in [cAMP] and protein kinase a in mammalian oocytes. Dev Biol 246: 441-451, 2002.

32. Webb RJ, Tinworth L, Thomas GM, Zaccolo M and Carroll J: Developmentally acquired PKA localisation in mouse oocytes and embryos. Dev Biol 317: 36-45, 2008.

33. Vossler MR, Yao H, York RD, Pan MG, Rim CS and Stork PJ: cAMP activates MAP kinase and Elk-1 through a B-Raf- and Rap1-dependent pathway. Cell 89: 73-82, 1997.

34. York RD, Yao H, Dillon T, Ellig CL, Eckert SP, McCleskey EW and Stork PJ: Rap1 mediates sustained MAP kinase activation induced by nerve growth factor. Nature 392: 622-626, 1998.

35. Sun QY, Breitbart H and Schatten H: Role of the MAPK cascade in mammalian germ cells. Reprod Fertil Dev 11: 443-450, 1999.

36. Fan HY and Sun QY: Involvement of mitogen-activated protein kinase cascade during oocyte maturation and fertilization in mammals. Biol Reprod 70: 535-547, 2004

37. Araki K, Naito K, Haraguchi S, Suzuki R, Yokoyama M, Inoue M, Aizawa S, Toyoda Y and Sato E: Meiotic abnormalities of c-mos knockout mouse oocytes: Activation after first meiosis or entrance into third meiotic metaphase. Biol Reprod 55: 1315-1324, 1996.

This work is licensed under a Creative Commons Attribution-NonCommercial-NoDerivatives 4.0 International (CC BY-NC-ND 4.0) License. 